\title{
ATIVIDADE ANTIMICROBIANA DE MALEIMIDAS E SEUS RESPECTIVOS ÁCIDOS ÂMICOS
}

\author{
João Vitor Partelli Pessin ${ }^{1}$; Leila Aley Tavares ${ }^{2}$; Débora Barreto Teresa Gradella ${ }^{3}$ \\ ${ }^{1}$ Acadêmico do curso de Farmácia da Universidade Federal do Espírito Santo, São Mateus, \\ ES - Brasil \\ ${ }^{2}$ Professora da Universidade Federal do Espírito Santo, Vitória, ES - Brasil \\ ${ }^{3}$ Professora da Universidade Federal do Espírito Santo (teresadb14@gmail.com), São \\ Mateus, ES - Brasil
}

Recebido em: 22/09/2018 - Aprovado em: 23/11/2018 - Publicado em: 03/12/2018 DOI: 10.18677/EnciBio_2018B94

\begin{abstract}
RESUMO
A resistência bacteriana vem se tornando uma das maiores ameaças à saúde, sendo necessário o desenvolvimento de novas substâncias bioativas. As imidas cíclicas têm atraído grande interesse dos pesquisadores devido aos efeitos biológicos que possuem. Assim, essa pesquisa teve como objetivo verificar a existência de atividade antimicrobiana de três maleimidas e seus respectivos ácidos âmicos, sendo elas: $N$-fenilmaleimida, $N$-(p-metilfenil) maleimida e $N$ cicloexilmaleimida. Para isso foi realizado o teste de avaliação da atividade antimicrobiana dessas substâncias frente aos microrganismos: Klebsiella pneumoniae (ATTCC 13883), Staphylococcus aureus (ATCC 25923), Pseudomonas aeruginosa (ATCC 9027) e Bacillus cereus (ATCC 11778). A N-cicloexilmaleimida, $N$-( $p$-metilfenil) maleimida e seu ácido âmico apresentaram inibição do crescimento maior do que $80 \%$ para Bacillus cereus e Staphylococcus aureus. Ncicloexilmaleimida inibiu totalmente o crescimento do Bacillus cereus, com CIM de $256 \mu \mathrm{g} / \mathrm{mL}$ apresentando ação bacteriostática e CBM de $512 \mu \mathrm{g} / \mathrm{mL}$. Nenhuma das substâncias testadas apresentou CIM inferior a $100 \mu \mathrm{g} / \mathrm{mL}$, não sendo consideradas, portanto com atividade biológica frente a estes microrganismos.
\end{abstract}

PALAVRAS-CHAVE: ácidos maleâmicos, atividade bactericida, imidas cíclicas.

\section{EVALUATION OF THE ANTIMICROBIAL ACTIVITY OF MALEIMIDES AND THEIR RESPECTIVE AMIC ACIDS}

\begin{abstract}
Bacterial resistance is becoming one of the greatest threats to health, being necessary the development of new bioactive substances. The cyclic imides have attracted great interest by the researchers due to the biological effects they have. Thus, this research aimed to verify the existence of antimicrobial activity of three maleimides and their respective amic acids, which are $N$-phenylmaleimide, $N-(p-$ methylphenyl) maleimide, $N$-cyclohexylmaleimide. For this was carried out the test of evaluation of the antimicrobial activity of these substances: Klebsiella pneumoniae (ATTCC 13883), Staphylococcus aureus (ATCC 25923), Pseudomonas aeruginosa (ATCC 9027) and Bacillus cereus (ATCC 11778). The $N$-cyclohexylmaleimide, $N$ - $(p$ methylphenyl) maleimide and its amic acid presented inhibition of growth greater than $80 \%$ to Bacillus cereus and Staphylococcus aureus. $\mathrm{N}$-cicloexylmaleimide totally inhibited the growth of Bacillus cereus, with CIM of $256 \mu \mathrm{g} / \mathrm{mL}$ presenting ENCICLOPÉDIA BIOSFERA, Centro Científico Conhecer - Goiânia, v.15 n.28; p.1178 2018
\end{abstract}


bacteriostatic action and CBM of $512 \mu \mathrm{g} / \mathrm{mL}$. None of the substances tested showed CIM less than $100 \mu \mathrm{g} / \mathrm{mL}$, not being considered therefore with biological activity against these microorganisms.

KEYWORDS: maleamic acids, bacterial activity, cyclic imides

\section{INTRODUÇÃO}

De acordo com a Organização Mundial da Saúde (OMS), a resistência bacteriana vem se tornando uma das maiores ameaças à saúde, sendo cada vez mais frequente o surgimento de microrganismos altamente resistentes e com raras opções de tratamento utilizando-se os medicamentos atualmente disponíveis (OMS, 2017; WHO, 2005). Tal resistência tem se dado principalmente devido ao uso inadequado de antibacterianos por parte da população sem a devida orientação do profissional da área de saúde como também pela ausência de práticas de prescrição fornecidas aos pacientes. Esse comportamento tem levado à demanda por antimicrobianos mais potentes ou ainda pelo uso da associação de diferentes medicamentos para o combate de tais bactérias (ROQUE et al., 2013; RODRIGUES et al., 2013).

A comunicação entre profissional e paciente, além do aumento do fluxo de informações pode vir a contribuir para melhorar este quadro de resistência bacteriana, além da intensificação de pesquisas voltadas para descoberta de novas substâncias com atividade biológica (LOUREIRO et al., 2016). Para contornar esse problema, torna-se necessária a busca por novos agentes antimicrobianos que possam ser empregados no tratamento de diversas doenças, causadas por microrganismos resistentes às terapias convencionais utilizadas.

As imidas constituem uma grande classe de compostos orgânicos caracterizados pela presença do grupo - $\mathrm{CO}-\mathrm{N}\left(\mathrm{R}^{\prime}\right)-\mathrm{CO}-$, onde $\mathrm{R}^{\prime}$ pode ser um átomo de hidrogênio, um grupo alquila ou um grupo arila. As imidas cíclicas podem ser classificadas em maleimidas, succinimidas, glutarimidas, ftalimidas, naftalimidas, dentre outras sub-classes e seus derivados. Esses compostos são geralmente obtidos através de síntese, sendo raramente encontrados na natureza (HARGREAVES et al.,1970; PIN; TAVARES, 2016).

Um método de síntese consiste na reação com anidridos de ácidos carboxílicos e amônia ou amina substituída. Na primeira etapa, obtém-se o ácido âmico que é, posteriormente, ciclizado na forma imídica por ação de um agente desidratante, obtendo-se assim a imida cíclica. O esquema 1 apresenta a sequência de reações para obtenção de uma maleimida.

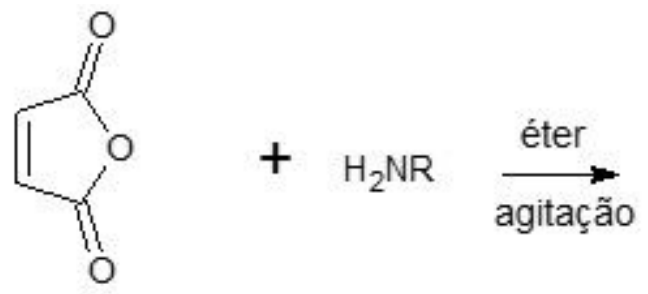

anidrido maleico

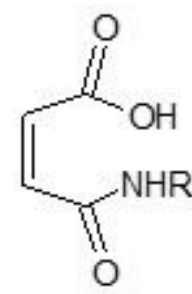

ácido âmico

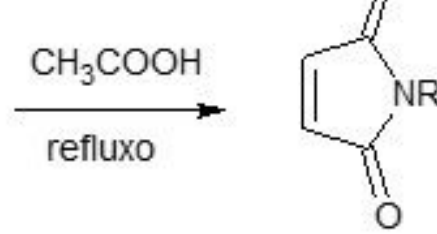

maleimida

FIGURA 1: Sequência de reações para obtenção de uma maleimida a partir do anidrido maleico. Fonte: adaptado de CECHINEL FILHO et al., 2003. 
A fácil obtenção das maleimidas aliada às suas atividades biológicas tem sido um fator importante para incentivar novas pesquisas nessa classe de compostos. Os efeitos biológicos das maleimidas e de compostos relacionados vêm sendo estudados há várias décadas. De acordo com Cechinel Filho e colaboradores, (2003) e Andricopulo e colaboradores, (1998), esses compostos são relacionados com diversas atividades biológicas, como bactericida, herbicida, antifúngica, inseticida, anti-inflamatória, hipnótica, diurética, sedativa e antitumoral. Hargreaves e colaboradores (1970) destacam especialmente as atividades antifúngica, antibacteriana e inseticida destes compostos e ainda podendo vir a apresentar atividade antinociceptiva (WALTER; ALMEIDA, 2013).

Com relação à atividade antimicrobiana, Cechinel Filho e colaboradores (2003) relataram que algumas $\mathrm{N}$-alquilarilmaleimidas são ativas contra bactérias patogênicas, freqüentemente encontradas em infecções do trato urinário ou intestinal humano, tais como Escherichia coli, Staphylococcus aureus, Klebsiella pneumoniae e outras. Alegaram ainda a atividade desses compostos contra alguns fungos leveduriformes e miceliais que causam diferentes micoses nos seres humanos, como Microsporum canis, Candida albicans, Penicilium, entre outros. Em outro trabalho, Zents e colaboradores (2002) descreveram que as maleimidas $\mathrm{N}$ propilmaleimida, $\mathrm{N}$-isopropilmaleimida e $\mathrm{N}$-butilmaleimida apresentaram bons resultados contra as bactérias Staphylococcus aureus e Escherichia coli. Neste estudo os autores sintetizaram e compararam as atividades antibacterianas de vinte e três maleimidas e oito succinimidas. Estas alquilmaleimidas apresentaram valores de concentração inibitória mínima (CIM) iguais a $8 \mathrm{~g} / \mathrm{mL}$ e $16 \mathrm{~g} / \mathrm{mL}$ para Staphylococcus aureus e Escherichia coli, respectivamente, enquanto as succinimidas apresentaram CIM igual ou superior a $128 \mathrm{~g} / \mathrm{mL}$.

Além das imidas cíclicas, seus ácidos âmicos correspondentes também tem sido estudados, como por exemplo, derivados do ácido $\mathrm{N}$-acil- $\mathrm{N}$-fenilmaleâmico que têm sido verificados com relação ao desenvolvimento de novos herbicidas. Além disso, derivados de fenilmaleimidas comprovaram ter atividade analgésica e efeito sobre o sistema nervoso central no tratamento de ansiedade e convulsões (ANDRICOPULO et al.,1998; CECHINEL FILHO et al., 2003).

Diante da potencial atividade de tal classe de compostos, esse trabalho teve como objetivo avaliar o efeito antimicrobiano de três maleimidas e seus respectivos ácidos âmicos frente a microrganismos Gram positivos e Gram negativos. Para isso foi determinada a CIM para os seis compostos estudados e a concentração bactericida mínima (CBM) para aqueles que apresentaram CIM.

\section{MATERIAL E MÉTODOS}

Os compostos estudados nesse trabalho foram a $\mathrm{N}$-fenilmaleimida (1), $\mathrm{N}$-(pmetilfenil) maleimida (3), $N$-cicloexilmaleimida (5) e seus respectivos ácidos âmicos; ácido $N$-fenilmaleâmico (2), ácido $N$-(p-metilfenil)maleâmico (4) e ácido $N$ cicloexilmaleâmico (6), apresentados na Figura 2. Todos os compostos foram previamente sintetizados e caracterizados pelo grupo de pesquisa coordenado pela Professora Leila A. Tavares que atua no desenvolvimento de projetos tais como a síntese e estudo biológico de imidas cíclicas. 
<smiles>O=C1C=CC(=O)N1c1ccccc1</smiles>

(1)

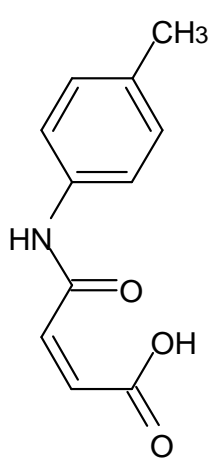

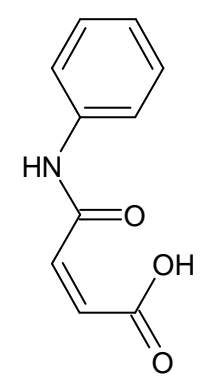

(2)<smiles>O=C1C=CC(=O)N1C1CCCCC1</smiles>

(5)<smiles>Cc1ccc(N2C(=O)C=CC2=O)cc1</smiles>

(3)<smiles>O=C(O)/C=C\C(=O)NC1CCCCC1</smiles>

(6)

(4)

FIGURA 2: Estrutura dos compostos estudados. $N$-fenilmaleimida (1), ácido $N$ fenilmaleâmico (2), $N$-(p-metilfenil)maleimida (3), ácido $N$-( $p$-metilfenil)maleâmico (4), $N$-cicloexilmaleimida (5) e ácido $N$-cicloexilmaleâmico (6)

\section{Atividade antimicrobiana}

A determinação da concentração inibitória mínima (CIM) das substâncias frente aos microrganismos testados foi realizada por ensaio de microdiluição em caldo nas concentrações de $1024,512,256,128,64,32,16,8,4$ e $2 \mu \mathrm{g} / \mathrm{mL}$ e a concentração bactericida mínima (CBM) foi realizada em método de crescimento em ágar.

O método CIM consistiu no preparo de diluições sucessivas das substâncias testadas em meios de cultivos próprios, inoculado com a bactéria em estudo, incubada e posteriormente verificada a menor concentração que inibiu o crescimento dos microrganismos.

\section{Preparo dos inóculos}

Para o preparo dos inóculos bacterianos, foram utilizadas bactérias Gram positivas: Staphyloloccus aureus (ATCC 25923) e Bacillus cereus (ATCC 11778), e bactérias Gram negativas: enterobactérias Escherichia coli (ATCC 8739) e Klebsiella pneumoniae (ATCC 13883), e bacilo não fermentador Pseudomonas aeruginosa (ATCC 9027). Todos os microrganismos são mantidos no laboratório de Microbiologia do CEUNES e foram doados pela Fundação Oswaldo Cruz.

Cada bactéria foi transferida do meio de manutenção para o meio Ágar MuellerHinton e incubada a $37^{\circ} \mathrm{C}$ por $18-24$ horas para ativação da respectiva cultura. Para o preparo do inóculo foram selecionadas de 4 a 5 colônias do microrganismo em 
Ágar Mueller-Hinton e transferidas para tubo de ensaio contendo $5,0 \mathrm{~mL}$ de solução $\mathrm{NaCl}$ 0,86\% estéril, seguidas de homogeneização. A densidade do inóculo seguiu densidade comparável com turvação 0,5 da escala de Mcfarland (NCCLS 1993).

\section{Avaliação da Concentração Inibitória Mínima (CIM)}

Após a escolha do solvente mais adequado (DMSO), uma solução da substância teste com o solvente foi preparada na concentração de $50 \mathrm{mg} / \mathrm{mL}$ (solução mãe). Diluições da substância foram preparadas com o meio TSB (Caldo Triptona de Soja) a partir da solução mãe na concentração de $1024 \mu \mathrm{g} / \mathrm{mL}$ até $2 \mu \mathrm{g} / \mathrm{mL}$ de droga. $O$ ensaio foi realizado em placa de 96 poços e controles positivo e negativo foram utilizados para análise do crescimento ou não do microrganismo.

Para o ensaio de microdiluição em placa, 100uL de caldo TSB (Caldo Triptona de Soja) foi adicionado nos poços correspondentes ao controle negativo de cada diluição e ao controle positivo e 100uL de cada diluição da substância foi adicionada na placa em triplicata e nos poços correspondentes ao teste de controle negativo. 100uL da suspensão bacteriana compatível com a turvação 0,5 da escala de Mcfarland foi adicionada ao controle positivo e nos poços correspondentes às diluições (em triplicata). Posteriormente a primeira leitura foi realizada em leitor de Elisa e a placa foi incubada à $37^{\circ} \mathrm{C}$ por 24 horas. Após período de incubação, os poços foram homogeneizados e uma nova leitura foi realizada. A diferença entre a segunda e a primeira leitura correspondeu ao crescimento do microrganismo e a concentração inibitória mínima foi determinada na menor concentração que houve inibição total do crescimento bacteriano.

Para descartar a possibilidade de interferência do solvente utilizado, antes da realização do ensaio de atividade antimicrobiana, foi realizado da mesma maneira como descrito acima, o mesmo teste utilizando-se apenas o solvente empregado, o meio de cultura e os microrganismos, com o objetivo de analisar a possível existência de atividade inibidora de crescimento bacteriano por parte do solvente.

\section{Avaliação da Concentração Bactericida Mínima (CBM)}

Para determinar a concentração bactericida mínima, foram selecionadas as culturas que apresentaram inibição total do desenvolvimento bacteriano no ensaio de CIM. Cada diluição da substância que apresentou inibição do crescimento no ensaio CIM foi inoculada em placa com meio Ágar Mueller-Hinton e incubadas a $37^{\circ} \mathrm{C}$ por 18-24 horas (subcultivo). Após incubação as culturas foram analisadas para verificação visual do crescimento bacteriano.

Para a interpretação dos resultados foi considerado que quando houve inibição no ensaio de CIM e crescimento do microrganismo na subcultura CBM, representado por colônias, significa que a substância exibe ação bacteriostática. Quando há inibição de crescimento no ensaio CIM e ausência de crescimento na subcultura CBM significa ação bactericida (SANTURIO et al., 2007).

\section{RESULTADOS E DISCUSSÃO}

De acordo com os resultados obtidos para a atividade antimicrobiana das maleimidas e os ácidos âmicos avaliados (Tabela 1), verificou-se que metade deles inibiu em algum grau o crescimento de pelo menos um microrganismo testado. No entanto, apenas a substância $\mathrm{N}$-cicloexilmaleimida foi capaz de inibir totalmente o crescimento de um dos microrganismos utilizados no estudo, o Bacillus cereus com CIM de $256 \mu \mathrm{g} / \mathrm{mL}$. Essa imida também apresentou inibição acima de $80 \%$ para o microrganismo Staphylococcus aureus. Outra substância que apresentou atividade ENCICLOPÉDIA BIOSFERA, Centro Científico Conhecer - Goiânia, v.15 n.28; p.1182 
inibitória do crescimento acima de $80 \%$ para as bactérias Bacillus cereus e Staphylococcus aureus foi a $\mathrm{N}$-( $p$-metilfenil) maleimida, conforme demonstrado na tabela 1. Antunes e colaboradores (2006) em testes realizados com imidas cíclicas na concentração de $200 \mu \mathrm{g} / \mathrm{mL}$ demonstraram que as substâncias testadas possuíram atividade antifúngica, no entanto as mesmas substâncias não apresentaram atividade antimicrobiana para as bactérias Staphylococcus aureus, Escherichia coli e Pseudomonas aeruginosa. Ainda, Al-Azzawi e Mahdi (2013) sintetizaram maleimidas com fração benzotiazol e produziram moléculas com atividades inibitória contra Staphylococcus aureus e Klebsiella pneumoniae.

TABELA 1. Atividade antimicrobiana das maleimidas e seus ácidos âmicos frente aos microrganismos estudados

\begin{tabular}{|c|c|c|c|c|c|}
\hline \multirow{2}{*}{$\begin{array}{l}\text { Substâncias } \\
\text { testadas }\end{array}$} & \multicolumn{5}{|c|}{ Microrganimos } \\
\hline & Bacillus cereus & $\begin{array}{c}\text { Staphylococcus } \\
\text { aureus }\end{array}$ & $\begin{array}{c}\text { Klebsiella } \\
\text { pneumoniae }\end{array}$ & $\begin{array}{c}\begin{array}{c}\text { Pseudomonas } \\
\text { aeruginosa }\end{array} \\
\end{array}$ & Escherichia coli \\
\hline$N$-fenilmaleimida & $(-)$ & $(-)$ & $(-)$ & $(-)$ & NR \\
\hline $\begin{array}{l}\text { Ácido } \\
\text { fenilmaleâmico }\end{array}$ & $(-)$ & $(-)$ & $(-)$ & $(-)$ & NR \\
\hline $\begin{array}{l}N \text { - }(p \text {-metilfenil }) \\
\text { maleimida }\end{array}$ & + & + & $(-)$ & $(-)$ & NR \\
\hline $\begin{array}{l}\text { Ácido } \quad N-(p- \\
\text { metilfenil)maleâmico }\end{array}$ & + & $(-)$ & $(-)$ & $(-)$ & NR \\
\hline$N$-cicloexilmaleimida & $X$ & + & $(-)$ & $(-)$ & NR \\
\hline $\begin{array}{l}\text { Ácido } \mathrm{N}- \\
\text { cicloexilmaleâmico }\end{array}$ & $(-)$ & $(-)$ & $(-)$ & $(-)$ & NR \\
\hline
\end{tabular}

X: Inibição total (100\%) em determinada concentração;+:inibição parcial;(-): inibição inferior a 80\%; NR - não realizado.

As substâncias $\mathrm{N}$-fenilmaleimida e seu respectivo ácido âmico não apresentaram inibição considerável (acima de $80 \%$ ) para nenhum microrganismo estudado. De acordo com Andricopulo et al. (1998) a baixa atividade para compostos tais como a $\mathrm{N}$-fenilmaleimida se deve ao fato de sua estrutura não apresentar um grupo metileno entre $\mathrm{o}$ anel imídico e o anel aromático, o que verificaram ser um fator estrutural importante para a atividade antibacteriana. Esse mesmo fato também foi confirmado pelos estudos de Zents et al. (2002), que encontraram atividade, frente ao $S$. aureus, cerca de 8 vezes menor para a $N$ fenilmaleimida $(\mathrm{CIM}=64 \mu \mathrm{g} / \mathrm{mL})$ quando comparada ao seu análogo contendo o grupo metila entre os anéis aromático e imídico $(\mathrm{CIM}=8 \mu \mathrm{g} / \mathrm{mL})$.

Dos três ácidos maleâmicos avaliados somente o $N$-( $p$-metilfenil) maleâmico inibiu acima de $80 \%$ o crescimento de Bacillus cereus. Nenhum outro microrganismo teve seu crescimento inibido significativamente por nenhum dos ácidos âmicos estudados. De fato, já era esperado por nosso grupo que estes compostos apresentassem atividade antibacteriana inferior às suas respectivas maleimidas. Embora, os efeitos biológicos de maleimidas e compostos relacionados vem sendo estudados há muitos anos, como pode ser evidenciado pela revisão da literatura realizada por Hargreaves et al. (1970), os ácidos âmicos tem chamado muito menos a atenção dos pesquisadores. No entanto, é importante que estes tenham sua atividade avaliada e divulgada para conhecimento.

A tabela 2 mostra a porcentagem de inibição do crescimento bacteriano em diferentes concentrações das substâncias que apresentaram efeito inibitório: $N-(p-$ metilfenil) maleimida, ácido $N$-( $p$-metilfenil) maleâmico e $N$-cicloexilmaleimida. Os 
resultados mostram que a menor concentração em que ocorreu inibição superior a $80 \%$ foi para a atividade da $N$-cicloexilmaleimida frente ao $B$. cereus. Essa ação inibitória ocorreu na concentração de $128 \mu \mathrm{g} / \mathrm{mL}$. No entanto, essa mesma substância só apresentou inibição do $S$. aureus a concentração de 1024 g/mL (91\% de inibição).

A substância $N$-(p-metilfenil) maleimida apresentou ação inibitória acima de $80 \%$ na concentração de $256 \mu \mathrm{g} / \mathrm{mL}$ para $S$. aureus e na concentração de 1024 $\mu \mathrm{g} / \mathrm{mL}$ para $B$. cereus. Na mesma concentração, $1024 \mu \mathrm{g} / \mathrm{mL}$, o ácido $N$-(p-metilfenil) maleâmico apresentou atividade inibitória de $86 \%$ para $B$. cereus (Tabela 2 ).

Cunha e colaboradores (2006) em estudo com succimidas e maleimidas relataram que as substâncias testadas apresentaram atividade antimicrobiana frente à bactérias Gram positivas e fungos, sendo que duas dessas substâncias obtiveram CIM de $1,5 \mu \mathrm{g} / \mathrm{mL}$ para Bacillus subtilis. Em estudo realizado por Dhivare e Rajput (2015) utilizando método de inibição em placa, derivados de imidas cíclicas demonstraram efeito inibitório do crescimento para Bacillus subtilis e Escherichia coli com tamanhos de halos inferiores aos obtidos pelo antibiótico padrão.

TABELA 2 - Porcentagem de inibição do crescimento bacteriano em diferentes concentrações das substâncias $N$-( $p$-metilfenil) maleimida, ácido $N$-(p-metilfenil) maleâmico e $N$-cicloexilmaleimida

\begin{tabular}{lcccccc}
\hline Concentração & \multicolumn{6}{c}{$\%$ de inibição do crecimento } \\
\cline { 2 - 7 } da substância & \multicolumn{2}{c}{$\begin{array}{c}\text { N-(p-metilfenil) } \\
\text { maleimida }\end{array}$} & $\begin{array}{c}\text { Ácido } N \text {-(p-metilfenil) } \\
\text { maleâmico }\end{array}$ & \multicolumn{1}{c}{$N$-cicloexilmaleimida } \\
& S. aureus & B. cereus & S. aureus & B. cereus & S. aureus & B. cereus \\
\hline $128 \mu \mathrm{g} / \mathrm{mL}$ & $(-)$ & $(-)$ & $(-)$ & $(-)$ & $(-)$ & 83 \\
$256 \mu \mathrm{g} / \mathrm{mL}$ & 84 & $(-)$ & $(-)$ & $(-)$ & $(-)$ & 100 \\
$512 \mu \mathrm{g} / \mathrm{mL}$ & 90 & 85 & $(-)$ & $(-)$ & $(-)$ & 100 \\
$1024 \mu \mathrm{g} / \mathrm{mL}$ & 98 & 94 & $(-)$ & 86 & 91 & 100 \\
\hline
\end{tabular}

(-): inibição do crescimento inferior a $80 \%$.

Nos ensaios realizados com os microrganismos Pseudomonas aeruginosa e Klebsiella pneumoniae, nenhuma maleimida e seus respectivos ácidos âmicos analisados apresentaram inibição acima de $80 \%$. A substância de maior ação inibitória foi a $N$-(p-metilfenil) maleimida, para ambos os microrganismos, porém apresentando inibição de $75 \%$ para Pseudomonas aeruginosa e $74 \%$ para Klebsiella pneumoniae, na concentração de $1024 \mu \mathrm{g} / \mathrm{mL}$. Em estudo da avaliação da atividade antibacteriana com diferentes maleimidas, Zents et al. (2002) também encontraram maior resistência do microrganismo $P$. aeruginosa quando comparado com $0 S$. aureus. Para a cicloexilmaleimida, por exemplo encontraram CIM $=16$ e $128 \mu \mathrm{g} / \mathrm{mL}$ para $S$. aureus e $P$. aeruginosa, respectivamente. Ainda, em estudo realizado com maleimidas ligadas a benzotiazol foi demonstrado que a atividade antibacteriana $e$ antifúngica de preparados maleimidas dependem da natureza do substituinte em suas moléculas. Os autores verificam que compostos que foram substituídos por grupos nitro mostraram alta atividade antibacteriana contra Klebsiella pneumoniae enquanto outras maleimidas não mostraram atividade contra esta bactéria ( $A L$ AZZAWI; MAHDI, 2013).

Jafari e colaboradores (2017) estudando a atividade antibacteriana de ftalimidas e succinimidas encontram um composto que mostrou inibição contra Escherichia coli na concentração de $16 \mu \mathrm{g} / \mathrm{mL}$. Porém, no presente estudo o ensaio 
para avaliar o efeito inibitório do DMSO frente ao crescimento da Escherichia coli demonstrou que este solvente apresentou $69 \%$ de inibição na concentração de $10 \%$. Dessa forma, o ensaio CIM das maleimidas e seus ácidos âmicos não foi realizado para E. coli. Esses resultados corroboram com o estudo de Wadhwani et al. (2008) que verificaram os efeitos de vários solventes no crescimento bacteriano e constataram que o DMSO exerceu alto potencial de inibição em concentrações acima de $4 \%$.

Os testes realizados com Bacillus cereus demonstraram que $N$ cicloexilmaleimida apresentou ação inibitória total do crescimento deste microrganismo e, portanto, foi determinada sua CIM em $256 \mu \mathrm{g} / \mathrm{mL}$ (Tabela 2). Diante deste resultado, realizou-se o ensaio CBM, concluindo-se que na concentração de $256 \mu \mathrm{g} / \mathrm{mL}$ o efeito é bacteriostático, uma vez que houve crescimento de colônias na placa. Entretanto, na concentração $512 \mu \mathrm{g} / \mathrm{mL}$ a substância exerceu efeito bactericida, (Figura 3).

Bacillus cereus é um microrganismo produtor de enterotoxinas termoestáveis e termolábeis, é responsável por causar certos tipos de patologias, tendo por principais características epidemiológicas os alimentos contaminados, especialmente alimentos contendo amido. Pode causar endoftalmite pós-traumática, doença emética que está associada à produção de uma toxina pré-formada no estádio térmico em alimentos, infecções oportunistas, principalmente no hospedeiro imunocomprometido e bacteremia. (BENNETT et al., 2013; MURRAY et al., 2014; TORTORA et al., 2017).

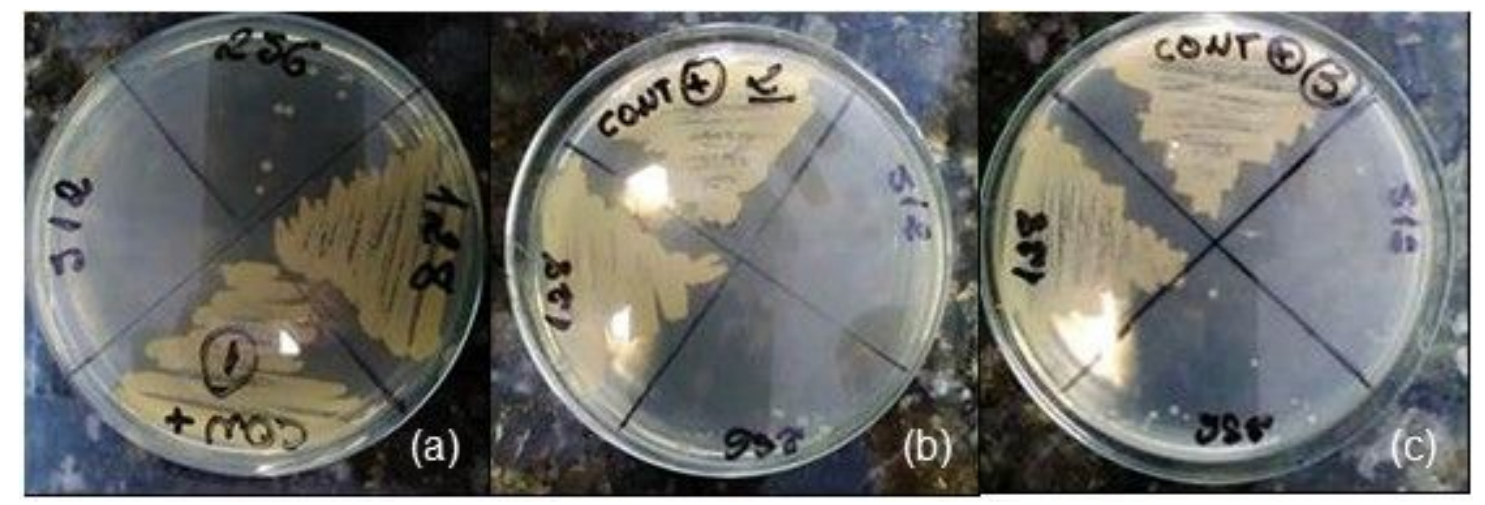

FIGURA 3: Avaliação da Concentração Bactericida Mínima (CBM) da substância $N$ cicloexilmaleimida para o microrganismo Bacillus cereus (ATCC 11778). Ensaio realizado em triplicata (placas a, b, e c). Fonte: própria (2017).

A $N$-cicloexilmaleimida é uma substância proveniente da síntese de ímidas cíclicas e apresentam importantes ações biológicas, principalmente como atividades bactericidas, fungicidas e inseticidas (ANDRICOPULO et al., 1998). Esta substância por sua vez pode vir a apresentar toxicidade quando utilizada em doses altas, tornando-se necessário realizar a sua avaliação. Em um estudo realizado por Potásio e colaboradores (2014), foi avaliada a toxicidade da cicloexilmaleimida e de seu respectivo ácido âmico frente à Artemia salina, constatando que a DL50\% correspondeu na concentração de $350,5 \mu \mathrm{g} / \mathrm{mL}$.

Rios e Recio (2005), ponderam que ao avaliar uma determinada substância frente a pesquisa da sua atividade antibacteriana não se deve utilizar concentrações acima de $1 \mathrm{mg} / \mathrm{mL}$ para extratos ou maior que $100 \mu \mathrm{g} / \mathrm{mL}$ para substâncias isoladas, pois para ser considerado biologicamente ativo é interessante que apresente 
atividade em concentrações inferiores a $100 \mu \mathrm{g} / \mathrm{mL}$ para extratos e inferiores a 10 $\mu \mathrm{g} / \mathrm{mL}$ para compostos isolados. Nesse sentido, no presente estudo nenhum composto pode ser considerado biologicamente ativo frente aos microrganismos utilizados, uma vez que nenhuma das substâncias apresentou CIM inferior a 100 $\mu \mathrm{g} / \mathrm{mL}$.

\section{CONCLUSÕES}

A partir da análise de três maleimidas e seus ácidos âmicos frente a quatro bactérias constatou-se que somente um composto, $N$-cicloexilmaleimida, inibiu totalmente o crescimento do Bacillus cereus, com CIM de $256 \mu \mathrm{g} / \mathrm{mL}$ e CBM de 512 $\mu \mathrm{g} / \mathrm{mL}$. Outros dois compostos, $N$-(p-metilfenil) maleimida e seu ácido âmico, apresentaram inibição parcial contra Staphylococcus aureus e Bacillus cereus. Entretanto, nenhuma substância obteve CIM inferior a $100 \mu \mathrm{g} / \mathrm{mL}$, não sendo, assim consideradas com atividade biológica frente aos microrganismos utilizados neste estudo.

\section{AGRADECIMENTO}

Agradecemos à Universidade Federal do Espírito Santo pela concessão da bolsa por meio do Programa de Institucional de Iniciação Científica no edital 2016/2017 e à Fundação de Amparo à Pesquisa e Inovação do Espírito Santo.

\section{REFERÊNCIAS}

AL-AZZAWI, A. M,; MAHDI, S. A. Synthesis and evaluation of antimicrobial activity of several new maleimides to benzothiazole moiety. Baghdad Science Journal, v. 10, p. 658-672, 2013. Dlsponível em: https://www.iasj.net/iasj?func=fulltext\&ald=77740.

ANDRICOPULO, A. D.; YUNES, R. A.; NUNES, R. J. Síntese e atividade antibacteriana de imidas cíclicas: 3,4-dicloromaleimidas e 3-cloro-4-substituídamaleimidas. Química Nova, v. 21, n. 5, p. 573-577, 1998. Disponível em:<http://dx.doi.org/10.1590/S0100-40421998000500008>. doi:10.1590/S010040421998000500008

ANTUNES, R. M. P.; LIMA, E. O.; PEREIRA, M. S. V.; CAMARA, C. A.; ARRUDA, T. A.; CATÃO, R. M. R.; BARBOSA, T. P.; NUNES, X. P.; DIAS, C. S.; SILVA, T. M. S. Atividade antimicrobiana "in vitro" e determinação da concentração inibitória mínina (CIM) de fitoconstituintes e produtos sintéticos sobre bactérias e fungos leveduriformes. Revista Brasileira de Farmacognosia, v. 16, n. 4, p. 517-24, 2006. Disponível em: <http://www.scielo.br/scielo.php?script=sci_arttext\&pid=S0102695X2006000400014\&lng=pt\&nrm=iso > . doi: 10.1590/S0102-695X2006000400014.

BENNETT, S. D.; WALSH, K. A.; GOULD, L. H. Foodborne Disease Outbreaks Caused by Bacillus cereus, Clostridium perfringens, and Staphylococcus aureusUnited States, 1998-2008. Food Safety, v. 57, n. 3, p. 1-9. 2013. Disponível em:<https://www.ncbi.nlm.nih.gov/pubmed/23592829>. doi: 10.1093/cid/cit244

BONA, E. A. M.; PINTO, F. G. S.; FRUET, T. K.; JORGE, T. C. M.; MOURA, A. C. Comparação de métodos para avaliação da atividade antimicrobiana e determinação da concentração inibitória mínima $(\mathrm{CIM})$ de extratos vegetais aquosos e etanólicos. Arquivos do Instituto Biológico, v. 81, n. 3, p. 218-225, 2014. Disponível em: 
<http://dx.doi.org/10.1590/1808-1657001192012>.

doi:

$10.1590 / 1808$

1657001192012

CECHINEL FILHO, V.; CAMPOS, F. C.; CORRÊA, R.; YUNES, R. A.; NUNES, R. J. Aspectos químicos e potencial terapêutico de imidas cíclicas: uma revisão da literatura. Química Nova, v. 26, n. 2, p. 230-241, 2003. Disponível em: <http://dx.doi.org/10.1590/S0100-40422003000200016>. doi: 10.1590/S010040422003000200016

CUNHA, D. S.; ÂNGELO, T.; SANTOS, A. O \& COSTA, N. G. Síntese e Atividade Antimicrobiana de Derivados Bromados de Maleimidas e Succinimidas. Reunião Anual da SBQ, 29, 2006. Disponível em: http://sec.sbq.org.br/cdrom/29ra/resumos/T0981-1.pdf

DHIVARE, R.S.; RAJPUT, S.S. Synthesis and antimicrobial activity of five membered cyclic imide derivatives of mono, di and tri substituted aromatic amines and napthyl amine. World Journal of Pharmaceutical, v. 4, n. 6, p. 1650-8, 2015. Disponível: https://www.researchgate.net/publication/283341892_SYNTHESIS_AND_ANTIMICR OBIAL_ACTIVITY_OF_FIVE_MEMBERED_CYCLIC_IMIDE_DERIVATIVES_OF_M ONO_DI_AND_TRI_SÜBSTITUTED_AROMATIC_AMINES_AND_NAPTHYL_AM̄IN $\mathrm{E}$

FREIRE, I. C. M.; PÉREZ, A. L. A. L.; CARDOSO, A. M. R.; MARIZ, B. A. L. A.; ALMEIDA, L. F. D.; CAVALCANTI, Y. W.; PADILHA, W. W. N. Atividade antibacteriana de Óleos Essenciais sobre Streptococcus mutans e Staphylococcus aureus. Revista Brasileira de plantas medicinais, v. 16, n. 2, p. 372-377, 2014. Disponível em:<http://dx.doi.org/10.1590/1983-084X/12_053>. doi: 10.1590/1983084X/12_053

HARGREAVES, M. K.; PRITCHARD, J. G.; DAVE, H. R.; Chemical Reviews, v. 70, n. 4, p. $439 \quad-\quad 469$, 1970. Disponível em: https://pubs.acs.org/doi/abs/10.1021/cr60266a001. doi: 10.1021/cr60266a001

JAFARI, E.; JARAH-NAJAFABADI, N. T.; JAHANIAN-NAJAFABADI, A.; POORIRANI, S.; HASSANZADEH, F.; SADEGHIAN-RIZI, S. Synthesis and evaluation of antimicrobial activity of cyclic imides derived from phthalic and succinic anhydrides. Research in PharmaceuticalSciences, v. 12, n. 6, p. 526-534, 2017. Disponível em: <https://www.ncbi.nlm.nih.gov/pmc/articles/PMC5691579>. doi: 10.4103/17355362.217433.

LOUREIRO, R. J.; ROQUE, F.; RODRIGUES, A. T.; HERDEIRO, M. T.; RAMALHEIRA. E. O uso de antibióticos e as resistências bacterianas: breves notas sobre a sua evolução. Revista Portuguesa de Saúde Pública, v. 34, n.1, p. 77-84, Lisboa, 2016. Disponível em: <http://dx.doi.org/10.1016/j.rpsp.2015.11.003>. doi: 10.1016/j.rpsp.2015.11.003

MURRAY, P.R.; ROSENTHAL, K.S.; PFALLER, M.A. Microbiologia médica. 7 ed. Rio de Janeiro: Elsevier, p. 213-214. 2014. 
ORGANIZAÇÃO MUNDIAL DA SAÚDE. OMS publica lista de bactérias para as quais se necessitam novos antibióticos urgentemente. Brasília, 2017. Disponível em: $<\mathrm{http}: / /$ www.paho.org/bra/index.php?option=com_content\&view=article\&id=5357:oms -publica-lista-de-bacterias-para-as-quais-se-necessitam-novos-antibioticosurgentemente\&ltemid $=812>$.

OSTROSKY, E.A.; MIZUMOTO, M.K.; LIMA, M.E.L.; KANECO, T.M.; NISHIKAWA, S.O.; FREITAS, B.R. Métodos para a avaliação da atividade antimicrobiana e determinação da concentração mínima inibitória (CIM) de plantas medicinais. Revista Brasileira de Farmacognosia, v.18, n. 2, 2008. Disponível em: <http://dx.doi.org/10.1590/S0102-695X2008000200026>. doi: 10.1590/S0102$695 \times 2008000200026$.

POTÁSIO, M.P.; TAVARES, L.A.; GONÇALVES, P.R.; VELLOSO, M.H.R.; SOUZA, N.D.A.; AGOSTINHO, J.A. Avaliação toxicológica da Cicloexilmaleimida e de seu respectivo Ácido Âmico frente a Artemia salina. Revista de Ciências Farmacêuticas Básica e Aplicada. v. 35, supl. 1, 2014. Disponível em: http://servbib.fcfar.unesp.br/seer/jornada/pdf/ACT04.pdf>. ISSN: 1808-4532 e-ISSN: 2179443X.

PIN, B. L; TAVARES, L. A. Estudo comparativo dos métodos e das condições para a obtenção de ftalimidas . Brazilian Journal of Production Engineering. v. 2, n. 2, p. 11-17, 2016. Disponível em: <file:///C:/Users/INFO/Downloads/14352-38767-2PB.pdf>.ISSN: $2447-5580$

RIOS, J. L.; RECIO, M.C. Medicinal plants and antimicrobial activity. Journal of Ethnopharmacology, v. 100, p. 80-84, 2005. Disponível em: https://scihub.tw/10.1016/j.jep.2005.04.025. doi: 10.1016/j.jep.2005.04.025.

RODRIGUES A. T.; ROQUE F.; FALCAO A.; FIGUEIRAS A.; HERDEIRO M. T. Understanding physician antibiotic prescribing behaviour: A systematic review of qualitative studies. International Journal of Antimicrobial Agents,v. 41, p. 203212 , 2013.

Disponível

em: <http://bdigital.ipg.pt/dspace/bitstream/10314/2488/1/ATR.Understanding\%20physici an\%20antibiotic\%20prescribing\%20behaviour.pdf>.

doi: 10.1016/j.ijantimicag.2012.09.003.

ROQUE F.; SOARES S.; BREITENFELD L.; LÓPEZ-DURÁN A.; FIGUEIRAS A.; HERDEIRO M.T.Attitudes of community pharmacists to antibiotic dispensing and microbial resistance: a qualitative study in Portugal. International Journal of Clinical Pharmacy, v. 35, n.3, p.417-424, 2013. Disponível em: https://link.springer.com/article/10.1007\%2Fs11096-013-9753-4. doi: 10.1007/s11096-013-9753-4.

SANTURIO, J. M.; SANTURIO, D. F.; POZZATTI P.; MORAES, C.; FRANCHIN, P.R.; ALVES, S. H. Atividade antimicrobiana dos óleos essenciais de orégano, tomilho e canela frente a sorovares de Salmonella enterica de origem avícola. Revista Ciência Rural, v. 37, n 3, p. 803-808, 2007. Disponível em: 
<http://dx.doi.org/10.1590/S0103-84782007000300031>. doi: 10.1590/S010384782007000300031.

TORTORA G. J.; FUNKE, B. R.; CASE, C. L. Microbiologia. 12. ed. Artmed, c. 25 p.724, 2017.2 Disponível em: <file:///C:/Users/INFO/Downloads/edoc.site_microbiologia-12-ediao-gerard-j-tortoraberdell-r-.pdf>.

WADHWANI, T.; DESAI, K.; PATEL, D.; LAWANI, D.; BAHALEY, P.; JOSHI, P.; KOTHARI, V. Effect of various solvents on bacterial growth in context of determining MIC of various antimicrobials. The Internet Journal of Microbiology, v.7, n. 1, 2008. Disponível em: <https://print.ispub.com/api/0/ispub-article/5909>.

WALTER, M. E.; ALMEIDA, V. L. QSAR-3D/CoMFA em compostos imídicos com atividade antinociceptiva. Química Nova, v. 36, n. 5, p. 691-696, 2013. Disponível em: <http://dx.doi.org/10.1590/S0100-40422013000500014>. doi: 10.1590/S010040422013000500014.

WHO - World Health Organization. Containing antimicrobial resistance. Geneva, Switzerland: WHO; 2005. (WHO Policy Perspectives on Medicines; 10). Disponível em: http://www.who.int/management/anmicrobialresistance.pdf.

ZENTS, F.; VALLA, A.; GUILLOU, R. L.; LABIA, R.; MATHOT, A. G.; SIROT, D. Synthesis and antimicrobial activities of $\mathrm{N}$-substituted imides. II Farmaco, v. 57, n. 5 , p. 421-426, 2002. Disponível em: <https://doi.org/10.1016/S0014-827X(02)01217X>. doi: 10.1016/S0014-827X(02)01217-X. 